\title{
Comparative Analysis of Alternative Fuels in Detonation Combustion
}

\author{
Muhammad Hanafi Azami ${ }^{1}$ and Mark Savill ${ }^{2}$ \\ Cranfield University, \\ Propulsion Engineering Centre, \\ School of Aerospace, Transport and Manufacturing, \\ Cranfield, Bedfordshire, MK43 OAL, \\ United Kingdom
}

\begin{abstract}
Detonation combustion prominently exhibits high thermodynamic efficiency which leads to better performance. As compared to the conventionally used isobaric heat addition in a Brayton cycle combustor, detonation uses a novel isochoric Humphrey cycle which utilises shocks and detonation waves to provide pressure-rise combustion. Such unsteady combustion has already been explored in wave rotor, pulse detonation engine and rotating detonation engine configurations as alternative technologies for the next generation of the aerospace propulsion systems. However, in addition to the better performance that the detonation mode of combustion offers, it is crucial to observe the environmental concerns as well. Therefore, this paper presents a one-dimensional numerical analysis for alternative fuels: Jet-A, Acetylene, Jatropha Bio-synthetic Paraffinic Kerosene, Camelina Bio-synthetic Paraffinic Kerosene, Algae Biofuel, and Microalgae Biofuel under detonation combustion conditions. For simplicity, the analysis is modelled using an open tube geometry. The analysis employs the Rankine-Hugoniot Equation, Rayleigh Line Equation, and Zel'dovichvon Neumann-Doering model and takes into account species mole, mass fraction, and enthalpies-of-formation of the reactants. Initially, minimum conditions for the detonation of each fuel are determined. Pressure, temperature, and density ratios at each stage of the combustion tube for different types of fuel are then explored systematically. Finally, the influence of different initial conditions is numerically examined to make a comparison for these fuels.
\end{abstract}

\section{Nomenclature}

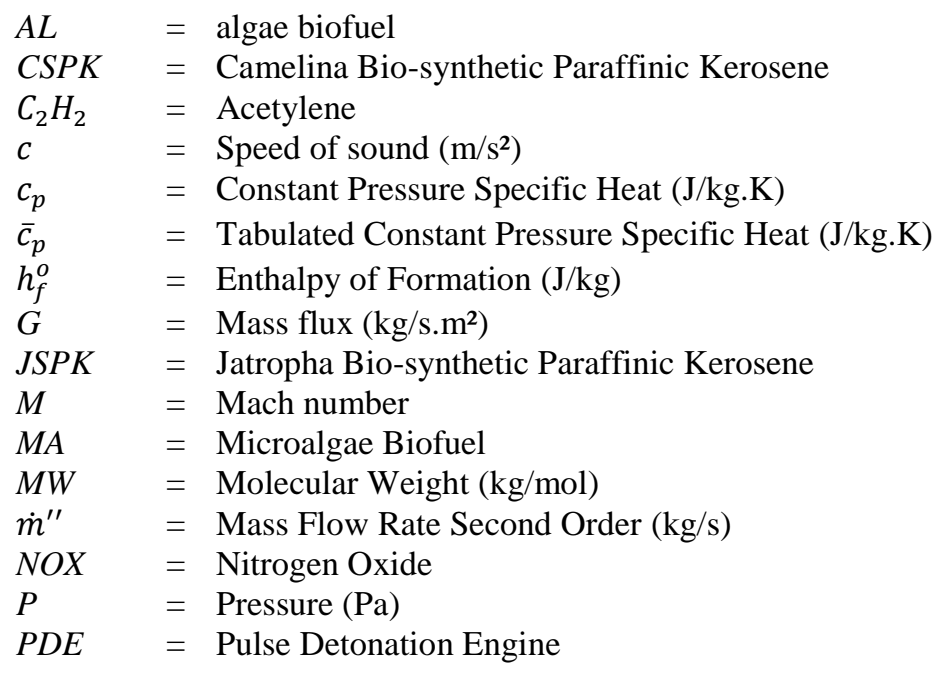

\footnotetext{
${ }^{1}$ Ph.D Researcher, SATM, Cranfield University, United Kingdom, AIAA Student-to-Professional Member.

${ }^{2}$ Professor, SATM, Cranfield University, United Kingdom.
}

American Institute of Aeronautics and Astronautics 


$\begin{array}{ll}q & =\text { Heat Addition }(\mathrm{J} / \mathrm{kg}) \\ R & =\text { Specific Gas Constant }(\mathrm{J} / \mathrm{kg} . \mathrm{K}) \\ R_{u} & =\text { Universal Gas Constant }(\mathrm{J} / \mathrm{kmol} . \mathrm{K}) \\ R D E & =\text { Rotating Detonation Engine } \\ T & =\text { Temperature }(\mathrm{K}) \\ T I T & =\text { Turbine Inlet Temperature }(\mathrm{K}) \\ V & =\text { Velocitry }(\mathrm{m} / \mathrm{s}) \\ V_{D} & =\text { Detonation Velocity }(\mathrm{m} / \mathrm{s}) \\ v & =\text { Specific Volume }\left(\mathrm{m}^{3} / \mathrm{kg}\right) \\ Y & =\text { Mass Fraction } \\ \gamma & =\text { Specific Heat Ratio } \\ \rho & =\text { Desnsity }\left(\mathrm{kg} / \mathrm{m}^{3}\right) \\ \chi & =\text { Mole Fraction }\end{array}$

$\begin{array}{ll}\text { Subscript } & \\ 1 & =\text { State } 1 \\ 2 & =\text { State } 2 \\ 2, & =\text { State } 2 \text { (arbiratary) } \\ i & =\text { Species number } \\ x & =\text { Axial direction }\end{array}$

\section{Introduction}

$\mathrm{D}$ etonation is a mode of combustion that can provide an extremely efficient means of combusting a fuel-oxidizer mixture ${ }^{1}$. It produces kinetic energy two orders of magnitude higher than a slower-burning deflagration and four orders of magnitude higher in terms of heat release ${ }^{2}$. It is thermodynamically more efficient and has a real potential for the next generation of aerospace propulsion systems ${ }^{3}$. Detonative combustion utilises shocks or detonation waves which act as valve between the detonation product fresh charges ${ }^{4}$ and the first practical application of non-isobaric heat addition in Humphrey cycle analysis ${ }^{5}$.

In a conventional Brayton cycle, the heat injection process has the maximum exergy which is fixed by the compressor's delivered pressure and the maximum temperature allowed by the cycle. Therefore, the exergy can be increased if the heat injection process follows different thermodynamic cycle path ${ }^{6}$. The resulting thermodynamic of Humphrey cycle is considered a modification to the Brayton cycle in which the constant-pressure heat addition process is replaced by a constant-volume heat addition process ${ }^{7}$. The Humphrey cycle is much more efficient than the Brayton cycle ${ }^{8}$ as a very rapid burning takes place. Due to the rapidity of this process, there is not enough time for pressure equilibration, and the overall process is, thus, thermodynamically closer to a constant volume process than the constant pressure process in the typical of conventional propulsion systems ${ }^{8}$. Thermodynamic efficiency of Chapmen-Jouget detonation has minimum entropy generation along the Hugoniot curve as compared to other combustion modes which appear to have a potential thermodynamic advantage ${ }^{9,10}$.

\section{Applications}

There are several intermittent devices that utilise unsteady flow to achieve pressure-rise combustion. These include pressure exchanger wave rotor, Pulse Detonation Engine (PDE), and Rotating Detonation Engine (RDE). Wave rotor is a non-steady flow device that compresses the combusted gas via unsteady shock waves rather than curved blades ${ }^{11}$ in the compressors. Wave rotor combustor is the combination of pressure-wave compression and expansion confined combustion within the rotor channels ${ }^{12}$. Shock waves are initiated when the rotor channels are in open and closed positions. Wave rotors have various advantages such as increased thermal efficiency by improving TIT, increased output power, minimised NOX emission due to the rapid combustion and gas dynamic quenching, self-cooled machine, and a uniformed exit velocity profile ${ }^{12-14}$. Despite that, its efficiency is reduced by friction and heat conduction as well as exposed to leakage problems of finite opening time of the channels ${ }^{11}$.

Pulse detonation engines (PDE) are pressure-rise and unsteady propulsion systems based on a repetitive mode of detonative combustion to develop thrust ${ }^{15-17}$. It differs from conventional propulsion systems from two aspects: unsteady operation and detonation combustion ${ }^{18,19}$. This promising new engine uses a detonation wave which is extremely fast and a thermodynamically efficient process for converting chemical energy in a combustible mixture 
to mechanical energy and tremendous kinetic energy $2,3,20,21$ as compared to deflagration wave in the combustion process $^{22}$.

In principle, pulse detonation engines are very simple devices that consist primarily of a tube in which a fuel/oxidizer mixture is initiated repeatedly at either the closed or the open end of a detonation chamber ${ }^{8}$ resulting in the ejection of combustion gases from the engine at very high velocities followed blowdown process and refill cycle $^{23}$. A cycle has three main components: detonation and blow down of burned gases, purging of the expanded burned products, and refilling of the tube with fresh reactants in a constant volume combustion chamber ${ }^{24,25}$. Most PDE studies employed unsteady gas dynamic calculations to determine the instantaneous pressures and forces acting on the surfaces of the device and integrate them over a cycle to determine thrust performance? ${ }^{7}$.

Alternatively, RDE attempts to improvise PDE in continuously detonation combustion. Detonation waves are continuously generated and propagated in azimuthal direction around an annular chamber at very high frequency ${ }^{26,27}$. Further improvements in RDE as compared to PDE which include small geometry are needed to achieve detonation, DDT devices are unnecessary, less time-consuming for filling and purging process, low vibration and noise.

In parallel to the better performance that the detonation mode of combustion offers, it is crucial and critical to observe the environmental concerns as well. However, discussions on the use of alternative fuels in detonation combustion are limited. Therefore, this paper presents a one-dimensional numerical analysis for alternative fuels: Jet-A, Acetylene, Jatropha Bio-synthetic Paraffinic Kerosene (JSPK), Camelina Bio-synthetic Paraffinic Kerosene (CSPK), Algae Biofuel, and Microalgae Biofuel under detonation combustion conditions.

\section{Theoretical Formulation and Numerical Framework}

The detonation wave is modeled as a normal shock wave (Zel'dovich-von Neumann-Doering (ZND) detonation wave) progressing into the undisturbed fuel-air mixture, which is nearly at rest at the combustor entry condition ${ }^{7}$, followed by combustion (Rayleigh type) in a uniformed cross-sectional area detonation tube ${ }^{28}$. The entire process is constrained by the Chapman-Jouguet condition which requires that the local Mach number at the termination of the heat addition region be one (sonic or choked flow) ${ }^{7}$. In CJ theory, chemical reactions are modeled as a heat release in an infinitesimally thin, shock front that brings the material from an initial state on the inert Hugoniot to the subsequent state, known as the CJ point ${ }^{5}$. The $\mathrm{CJ}$ point is also the tangent from the initial state to the final state on a $\mathrm{p}-\mathrm{v}$ diagram that is equal to the Rayleigh heating process. The intrinsically unsteady nature of the flow field associated with the detonation process has made it difficult to evaluate the relative performance with respect to conventional steady-flow propulsion systems and require unsteady analysis using computational approach ${ }^{25,29,30}$.

For simplicity, the analysis is carried out in an open-ended constant-area tube geometry for a single cycle. Appropriate expressions including the Rankine-Hugoniot Equation, Rayleigh Line Equation, species mole \& mass fraction of the reactants, enthalpies-of-formation, ideal-gas normal shock equations and iterations have been incorporated in the modelling. The analysis and calculations have been verified using previously published examples ${ }^{31}$. The assumptions that are utilised in this approach are: (1) the upstream and downstream boundaries lie in the control volume where there are no temperatures or species concentration gradients; (2) uniform onedimensional flow under adiabatic conditions, (3) body forces and dissociation of the products are neglected, and (4) the normal shocks relation is considered. Some of the necessary thermochemical properties of the alternative fuels used for the analysis are included in the appendix.

One-dimensional analysis with the variation of mass flux, initial temperature and pressure are calculated from conservation of mass and momentum, thus, Rayleigh line yields the following relationship:

$$
\frac{P_{2}-P_{1}}{\frac{1}{\rho_{2}}-\frac{1}{\rho_{1}}}=\frac{P_{2}-P_{1}}{v_{2}-v_{1}}=-\dot{m}^{\prime \prime 2}
$$

Combining conservation of mass, momentum and energy with heat addition, yield:

$$
\frac{\gamma}{\gamma-1}\left(P_{2} v_{2}-P_{1} v_{1}\right)-\frac{1}{2}\left(P_{2}-P_{1}\right)\left(v_{1}+v_{2}\right)-q=0
$$

From Rayleigh Line, $P_{2}$ is:

$$
P_{2}=P_{1}+\dot{m}^{\prime \prime 2}\left(v_{1}-v_{2}\right)
$$


Substitute into Rankine-Hugonoit Curve, yield:

$$
\left.\frac{\gamma}{\gamma-1}\left[\left(P_{1}+\dot{m}^{\prime \prime 2}\left(v_{1}-v_{2}\right)\right) v_{2}-P_{1} v_{1}\right)\right]-\frac{1}{2}\left(\left(P_{1}+\dot{m}^{\prime \prime 2}\left(v_{1}-v_{2}\right)\right)-P_{1}\right)\left(v_{1}+v_{2}\right)-q=0
$$

Expanding and convert to quadratic equation yield:

$$
a v_{2}^{2}+b v_{2}+c=0
$$

Where,

$$
\begin{gathered}
a=\frac{1+\gamma}{2(1-\gamma)} \dot{m}^{\prime \prime 2} \\
b=\frac{\gamma}{\gamma-1}\left(P_{1} v_{1}+\dot{m}^{\prime \prime 2} v_{1}\right) \\
c=\frac{\gamma}{1-\gamma} P_{1} v_{1}-1 / 2 \dot{m}^{\prime \prime 2} v_{1}^{2}-q \\
v_{1}=\frac{R_{1} T_{1}}{P_{1}}
\end{gathered}
$$

And solve for $v_{2}$,

$$
v_{2}=\frac{-b \pm \sqrt{b^{2}-4 a c}}{2 a}
$$

$P_{2}, V_{x, 2}, T_{2}, c_{2}$ and $M_{2}$ for every $v_{2}$ are calculated accordingly. Next, detonation velocity in stoichiometric condition and gas-mixture properties at the shock front (state 2') are estimated by applying stoichiometric relation:

$$
C_{x} H_{y}+a\left(O_{2}+3.76 N_{2}\right) \rightarrow x \mathrm{CO}_{2}+(y / 2) \mathrm{H}_{2} \mathrm{O}+3.76 a N_{2}
$$

Every species mole and mass fraction are calculated and thermochemical properties such as specific heat, gas constant and specific heat ratio are obtained using these relations:

$$
\begin{gathered}
c_{p, 1}=\frac{\sum_{\text {state } 1} \chi_{i} \bar{c}_{p, i}}{M W_{1}} \text { and } c_{p, 2}=\frac{\sum_{\text {state } 2} \chi_{i} \bar{c}_{p, i}}{M W_{2}} \\
R_{2}=\frac{R_{u}}{M W_{2}} \text { and } \gamma_{2}=\frac{c_{p, 2}}{c_{p, 2}-R_{2}}
\end{gathered}
$$

Heat formation, q, is calculated using enthalpies-of-formation in the tabulated table which is converted to a mass basis.

$$
q \equiv \sum_{\text {state } 1} Y_{i} h_{f, i}^{0}-\sum_{\text {state } 2} Y_{i} h_{f, i}^{0}
$$

Detonation velocity and temperature at state 2 are determined using:

$$
\begin{gathered}
v_{D}=\left[2 \gamma_{2} R_{2}\left(\gamma_{2}+1\right)\left(\frac{c_{p, 1}}{c_{p, 2}} T_{1}+\frac{q}{c_{p, 2}}\right)\right]^{1 / 2} \\
T_{2}=\frac{2 \gamma_{2}^{2}}{\gamma_{2}+1}\left(\frac{c_{p, 1}}{c_{p, 2}} T_{1}+\frac{q}{c_{p, 2}}\right)
\end{gathered}
$$

Using ideal-gas normal-shock and knowing the mixture specific-heat ratio and Mach number at initial state, these relations are used to find state 2':

$$
\frac{P_{2 \prime}}{P_{1}}=\frac{1}{\gamma+1}\left[2 \gamma M_{1}^{2}-(\gamma-1)\right]
$$




$$
\begin{gathered}
\frac{T_{2 \prime}}{T_{1}}=\left[2+M_{1}^{2}(\gamma-1)\right] \frac{2 \gamma M_{1}^{2}-(\gamma-1)}{(\gamma+1)^{2} M_{1}^{2}} \\
\frac{\rho_{2 \prime}}{\rho_{1}}=\frac{(\gamma+1) M_{1}^{2}}{(\gamma-1) M_{1}^{2}+2}
\end{gathered}
$$

While, $V_{x, 2}$ is calculated using conservation of mass. The state-2 Mach number should be equal to one (upper CJpoint).

$$
\begin{gathered}
\dot{m^{\prime \prime}}=\rho_{1} V_{x, 1}=\rho_{2,} V_{x, 2 \prime} \\
M_{2 \prime}=\frac{V_{x, 2 \prime}}{\sqrt{\gamma_{2 \prime} R_{2 \prime} T_{2 \prime}}}
\end{gathered}
$$

\section{Results and Discussions}

\section{A. Conditions for detonation}

Initially, three parameters have been analysed for fuel comparison; pressure ratio, temperature ratio and density ratio with respect to initial conditions at different stages of detonation tube. However, several necessary steps need to be taken prior to the analysis. Firstly, all fuels must achieve detonation velocity first either by increasing the mass flux or the initial temperature. The minimum initial temperature and mass flux before every alternative fuel can be detonated are shown in Table 1. It should be noted that heavy hydrocarbon fuels such as Jet-A and biofuels are difficult to detonate, thus require pre-heating or accelerated to a high velocity. Secondly, the flow is choked at stage 3. Lastly, stoichiometric combustion takes place.

From Table 1, it is observed that ACN fuel was the easiest to detonate, where it had the lowest minimum temperature and mass flux. In contrast, MA fuel was the most difficult to detonate where it required high temperature and mass flux. Thus, its detonation velocity has the highest value. All biofuels have high heat addition as tabulated in Table 2. This is believed to be due to the large molecular structure of biofuels. These properties are calculated based on the summation of each species formed to find its detonation velocity at arbitrary 2' state using a ZND model.

Table 1. Minimum initial temperature \& mass flux for detonation

\begin{tabular}{|c|c|c|c|c|c|c|}
\hline & $\mathbf{A C N}$ & JET-A & MA & JSPK & CSPK & AL \\
$\boldsymbol{C}_{\mathbf{2}} \boldsymbol{H}_{\mathbf{2}}$ & $\boldsymbol{C}_{\mathbf{1 2}} \boldsymbol{H}_{\mathbf{2 4}}$ & $\boldsymbol{C}_{\mathbf{1 2}} \boldsymbol{H}_{\mathbf{2 0}} \boldsymbol{O}_{\mathbf{5}} \boldsymbol{N}_{\mathbf{2}}$ & $\boldsymbol{C}_{\mathbf{1 2}} \boldsymbol{H}_{\mathbf{2 6}}$ & $\boldsymbol{C}_{\mathbf{1 2}} \boldsymbol{H}_{\mathbf{2 5 . 4}}$ & $\boldsymbol{C}_{\mathbf{1 2}} \boldsymbol{H}_{\mathbf{1 9}} \boldsymbol{O}_{\mathbf{3}} \boldsymbol{N}$ \\
\hline $\boldsymbol{T}_{\mathbf{1}}(\boldsymbol{K})$ & 300 & 1467 & 2000 & 1700 & 1700 & 2000 \\
\hline $\begin{array}{c}\mathbf{G} \\
\left(\mathbf{k g} / \boldsymbol{s . ~}^{\mathbf{2}}\right)\end{array}$ & 2612 & 3000 & 5800 & 4400 & 4400 & 4800 \\
\hline $\boldsymbol{\gamma}_{\mathbf{1}}$ & 1.379 & 1.267 & 1.209 & 1.226 & 1.225 & 1.214 \\
\hline $\boldsymbol{Q}_{\mathbf{1}}(\boldsymbol{J})$ & 3399.6 & 3648.4 & 12996.9 & 12744.9 & 127728.0 & 12622.4 \\
\hline $\boldsymbol{V}_{\boldsymbol{D}}(\boldsymbol{m} / \boldsymbol{s})$ & 1997.95 & 2398.9 & 3334.7 & 3244.2 & 3241.5 & 3289.5 \\
\hline
\end{tabular}

Table 2. Thermochemical properties during the reaction

\begin{tabular}{|c|c|c|c|c|c|c|}
\hline \multicolumn{7}{|l|}{ State 1 (Reactant) } \\
\hline & ACN & JET-A & MA & JSPK & CSPK & AL \\
\hline $\boldsymbol{c}_{\boldsymbol{p} \mathbf{1}}$ & 1.057 & 1.294 & 1.037 & 1.156 & 1.158 & 1.099 \\
\hline $\boldsymbol{q}_{\mathbf{1}}$ & 613.87 & 608.75 & 3412.21 & 2140.06 & 2147.67 & 2910.72 \\
\hline $\boldsymbol{\gamma}_{\mathbf{1}}$ & 1.379 & 1.267 & 1.209 & 1.226 & 1.225 & 1.214 \\
\hline State 2 (Product) & \multicolumn{5}{l|}{} \\
\hline $\boldsymbol{c}_{\boldsymbol{p} \mathbf{2}}$ & 1.443 & 1.531 & 1.797 & 1.923 & 1.915 & 1.79 \\
\hline $\boldsymbol{q}_{\mathbf{2}}$ & -2785.73 & -3039.65 & -9584.74 & -10604.9 & -10580.4 & -9711.72 \\
\hline $\boldsymbol{R}_{\mathbf{2}}$ & 0.279 & 0.289 & 0.261 & 0.273 & 0.271 & 0.258 \\
\hline $\boldsymbol{\gamma}_{\mathbf{2}}$ & 1.24 & 1.232 & 1.17 & 1.165 & 1.165 & 1.168 \\
\hline
\end{tabular}




\section{B. Comparative detonation analysis of alternative fuels using ZND model}

Next, every fuel is calculated and tabulated for comparison. Figure 1 demonstrates the trend for pressure ratio achieved by different alternative fuels at the minimum conditions of temperature, pressure and mass flux. It is clearly indicated that there are two existing separate regions. One region is accompanied by MA, CSPK, JSPK and AL biofuels while a lower region consists of Jet-A and ACN fuel. However, CSPK and JSPK Biofuel are difficult to be distinguished and have almost identical values. All fuels showed an increase in the pressure ratio at the early stage as the fuels approach the shock before starting to decrease again. These graphs have also indicated that biofuels are quite sensitive to detonation where there are large changes in pressure ratio.

The variation of temperature ratio takes a different trend as shown in Fig. 2. All fuels tend to increase in temperature along the tube. The temperature ratio increases rapidly before the shock and it is relaxed after the shock. The similar two regions obliviously existed in the temperature ratio variations. CSPK and JSPK Biofuels achieve the highest change in temperature after the shock is taken place. This followed by MA, AL, Jet-A and CAN fuels. Based on these trends, despite a pressure-rise in detonation combustion, temperature rise can also be achieved.
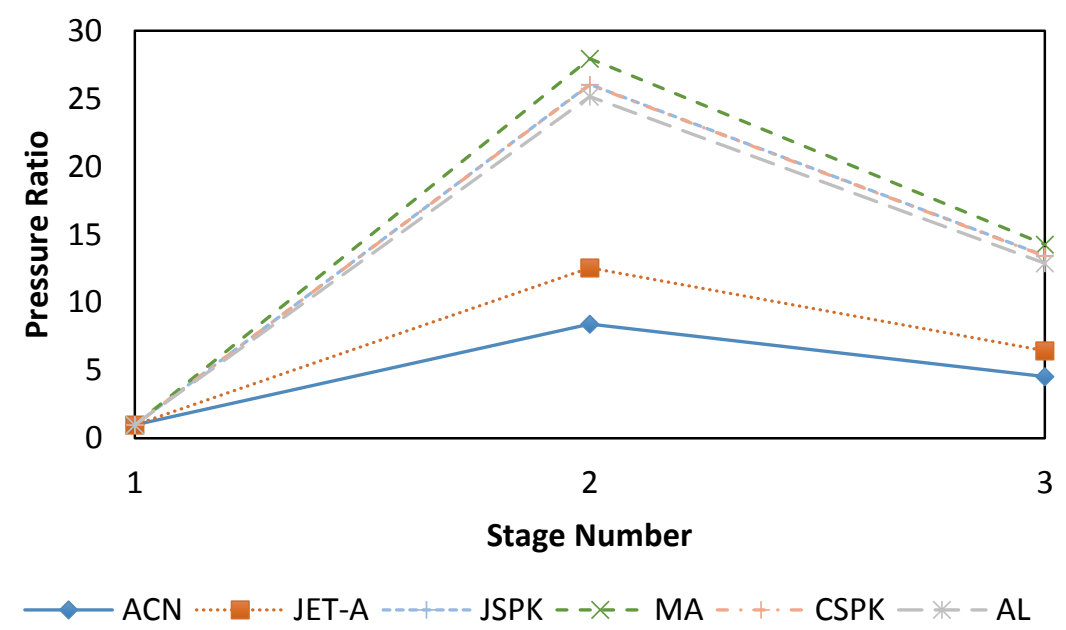

Figure 1. Pressure ratio at different stage

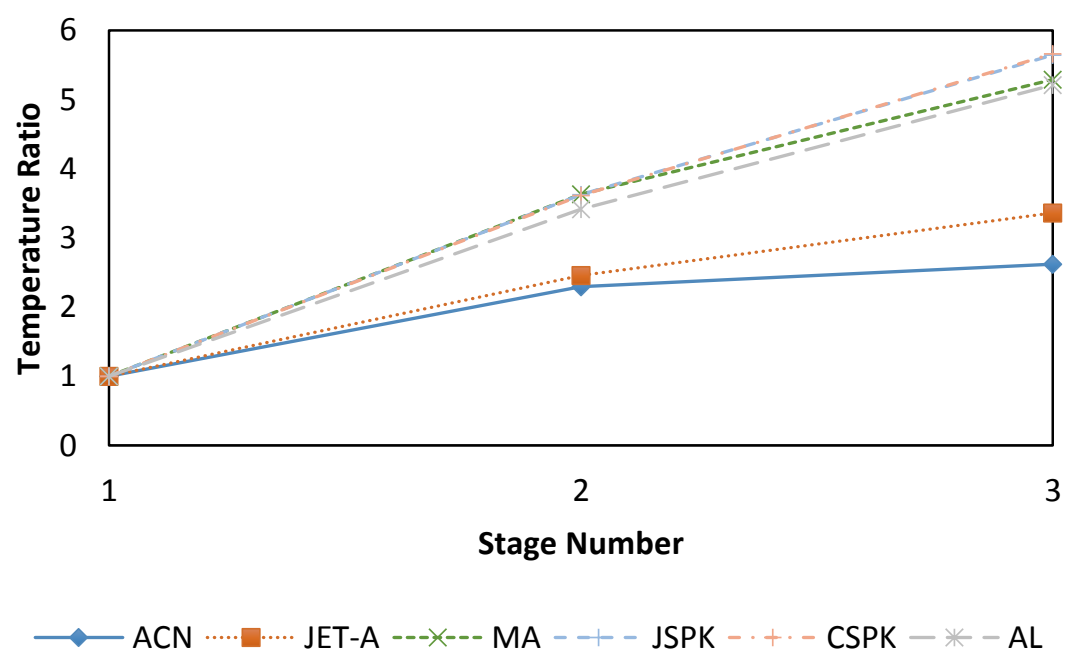

Figure 2. Temperature ratio at different stage 
Likewise, density ratio trends demonstrate the similar trends as in the pressure ratio trend as shown in Fig. 3. All biofuels experienced the largest change in density as compared to other types of fuels. ACN has the lowest change at the arbitrary shock wave. These changes are not very significant in the burned gas stage (stage number 3 ). Several factors affect these changes such as the molecular structure of the fuel, enthalpy-formation of the reaction, and the initial state condition for detonation.

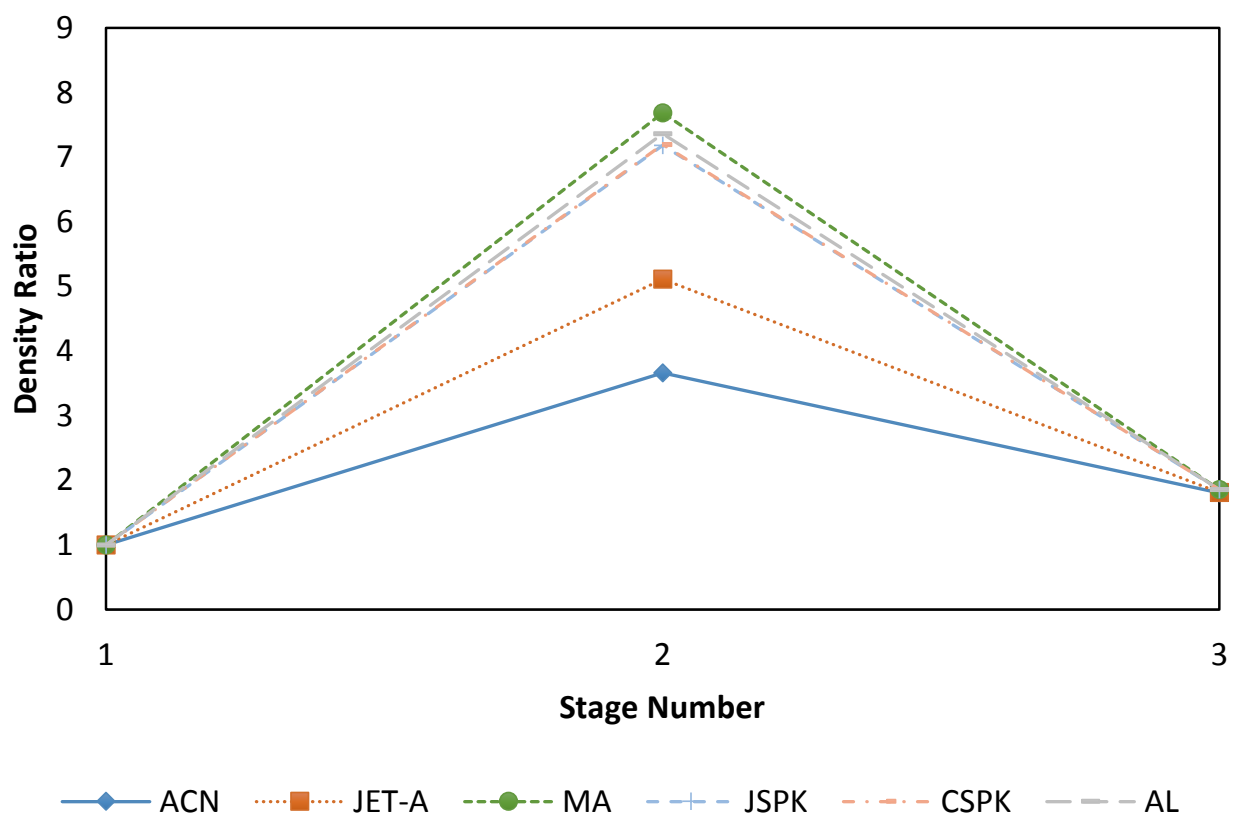

Figure 3. Density ratio at different stage

\section{Influence of various initial conditions}

Initial conditions are the crucial driving factors of the burned gas downstream. This section discusses the effects of various upstream initial conditions such as the mass flux, temperature and pressure to the variation of pressure, temperature, specific volume, and Mach number ratios. The ratios which are presented are described as the parameter of burned gas to the parameter of unburned gas. Two distinct physical phenomena occurred which are weak and strong detonation (two values obtained from the quadratic functions in Eq. (5)). These are also based on the upper Chapman-Jouget point. Turns ${ }^{31}$ have characterised that strong detonation is achieved when the burned gas velocity achieved a subsonic speed (above the upper CJ-point) while weak detonation occurred when the burned gas velocity at supersonic speed (below the upper CJ-point). However, only the influence of strong detonation results is presented and discussed. Acetylene fuel analysis is excluded in the discussion because it is hardly comparable due to the highly sensitive to initial changes.

\section{Effects of initial mass flux}

Comparisons of these alternative fuels are examined to demonstrate the changes of the above-mentioned ratios as the mass flux increases. Initially, the initial conditions such as the pressure and temperature are fixed to 1atm and $2000 \mathrm{~K}$ respectively. These parameters are chosen when all fuels achieved its detonation velocity. Both of pressure and temperature ratios illustrate a linear increment for all fuels as the mass flux increases as shown in Fig. 4 and Fig. 5. Jet-A fuel resulted in the highest pressure ratio while JSPK and CSPK showed the highest temperature ratio at each mass flux. JSPK and CSPK fuels are barely differentiated due to their alike molecular formulae. Jet-A fuel also showed the largest change in temperature ratio as the initial mass flux increases. 


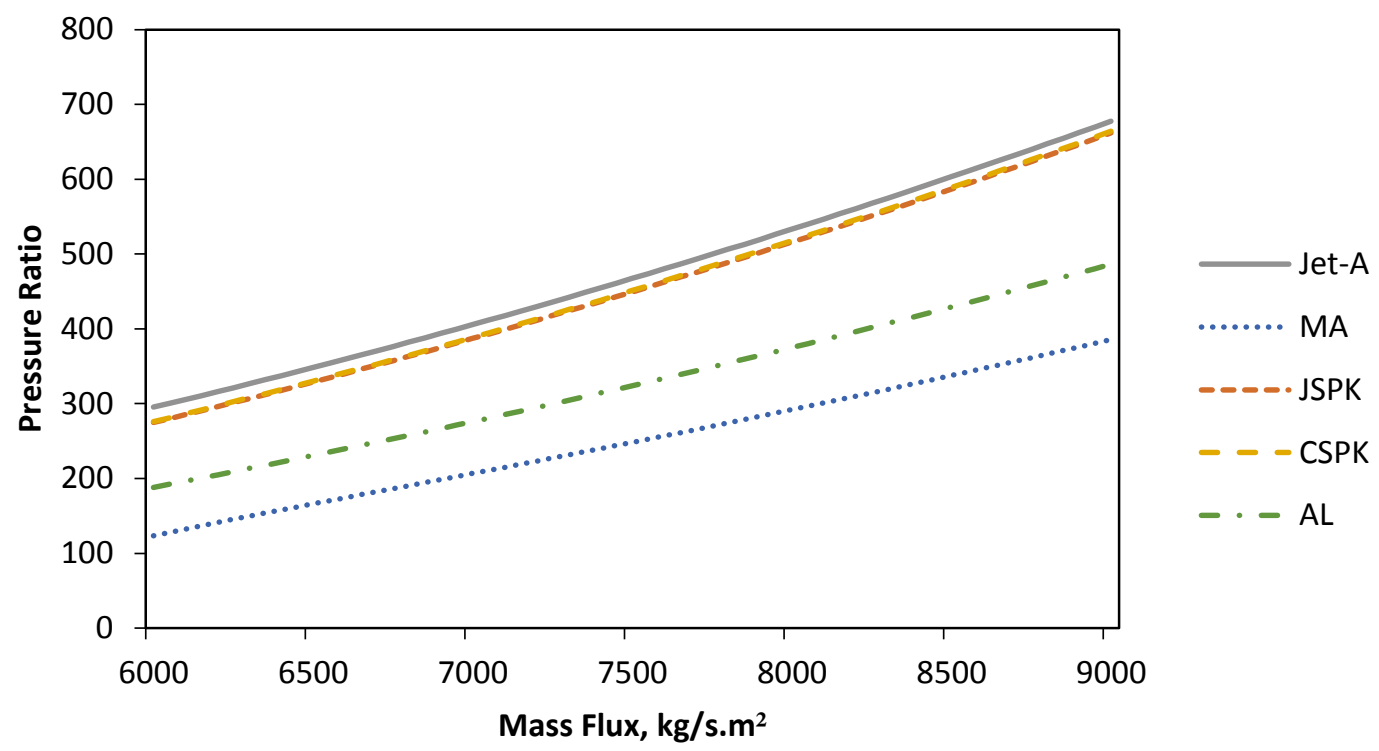

Figure 4. Comparison of pressure ratio at different initial mass flux under influence of strong detonation $(\mathrm{P}=1 \mathrm{~atm}, \mathrm{~T}=\mathbf{2 0 0 0 K})$.

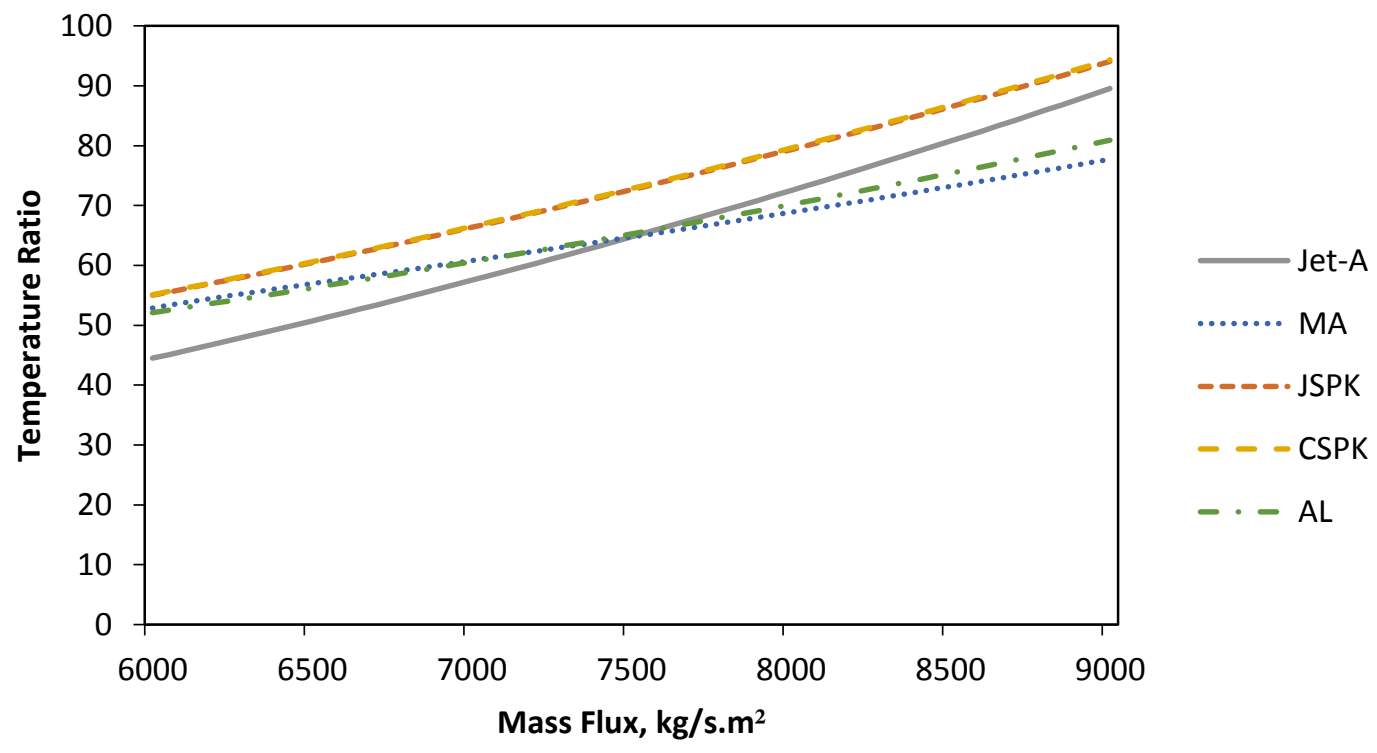

Figure 5. Comparison of temperature ratio at different initial mass flux under influence of strong detonation $(P=1$ atm, $T=2000 K)$.

Figure 6 and Fig. 7 illustrate the changes of specific volume and Mach number ratios. All alternative fuels have specific volume reduction after the shock wave under the influence of strong detonation wave. However, there are not many changes in Jet-A fuel observed for these two ratios. Conversely, MA fuel has shown quite a significant change in specific volume and Mach number ratios at the low mass fluxes as compared to higher initial mass flux. 


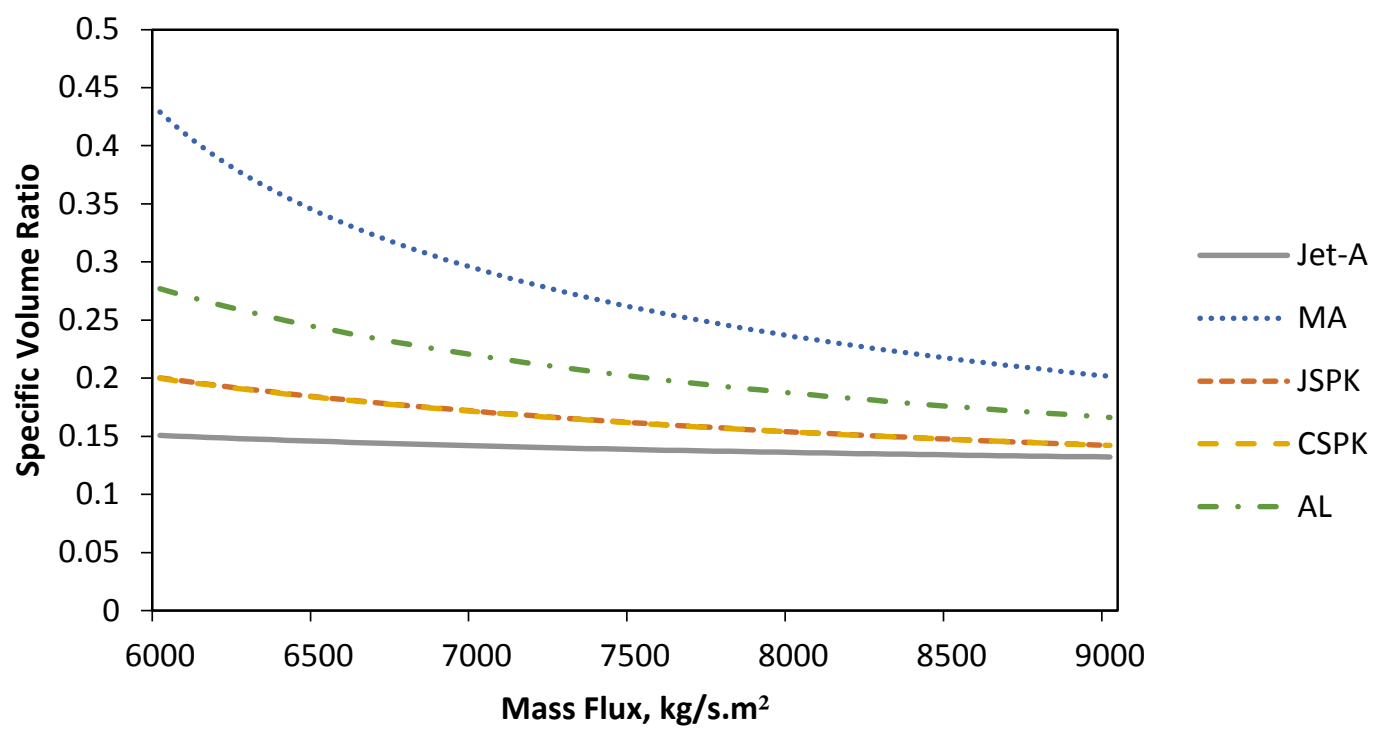

Figure 6. Comparison of specific volume ratio at different initial mass flux under the influence of strong detonation ( $\mathrm{P}=\mathbf{1}$ atm, $\mathrm{T}=\mathbf{2 0 0 0 K})$.

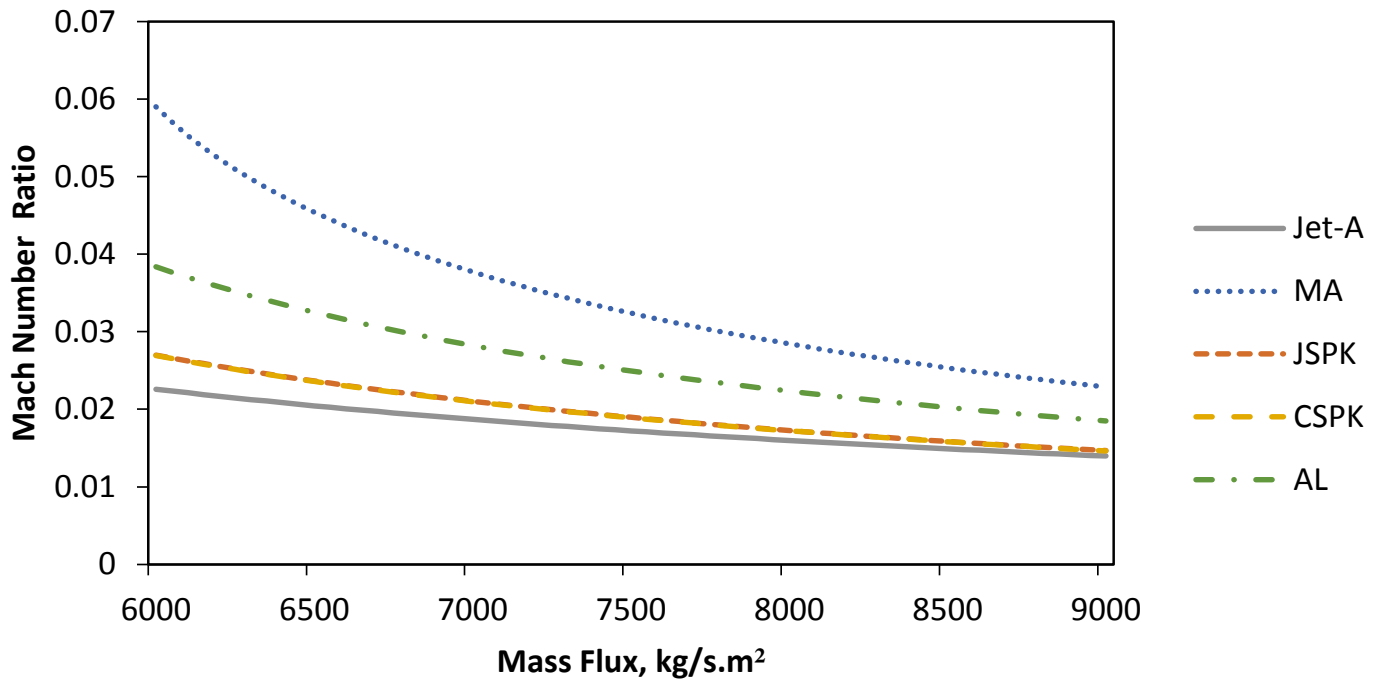

Figure 7. Comparison of Mach number ratio at different initial mass flux under the influence of strong detonation $(\mathrm{P}=\mathbf{1} \mathrm{atm}, \mathrm{T}=\mathbf{2 0 0 0 K})$.

\section{Effects of initial temperature}

The effect of initial temperature to the pressure, temperature, specific volume and Mach number ratios are discussed in this section. Initial conditions such as pressure and mass flux remained fixed while initial temperatures are varied. The variation of initial temperature starts from $2000 \mathrm{~K}$ as this is the minimum temperature for MA and AL fuels are detonated.

Figure 8 and Fig. 9 illustrate the changes of pressure and temperature ratios respectively. The variations showed the similar trends as shown in the effect of initial mass flux. However, the changes of pressure and temperature ratios are not that significant with the variation of initial temperature compared to the variation of mass flux. This indicates 
that mass flux has more effects to pressure and temperature ratios. These are comparable with the gradient of each graph. Likewise, Jet-A fuel showed substantial changes on temperature ratio compared to other alternative fuels as the initial temperature increases.

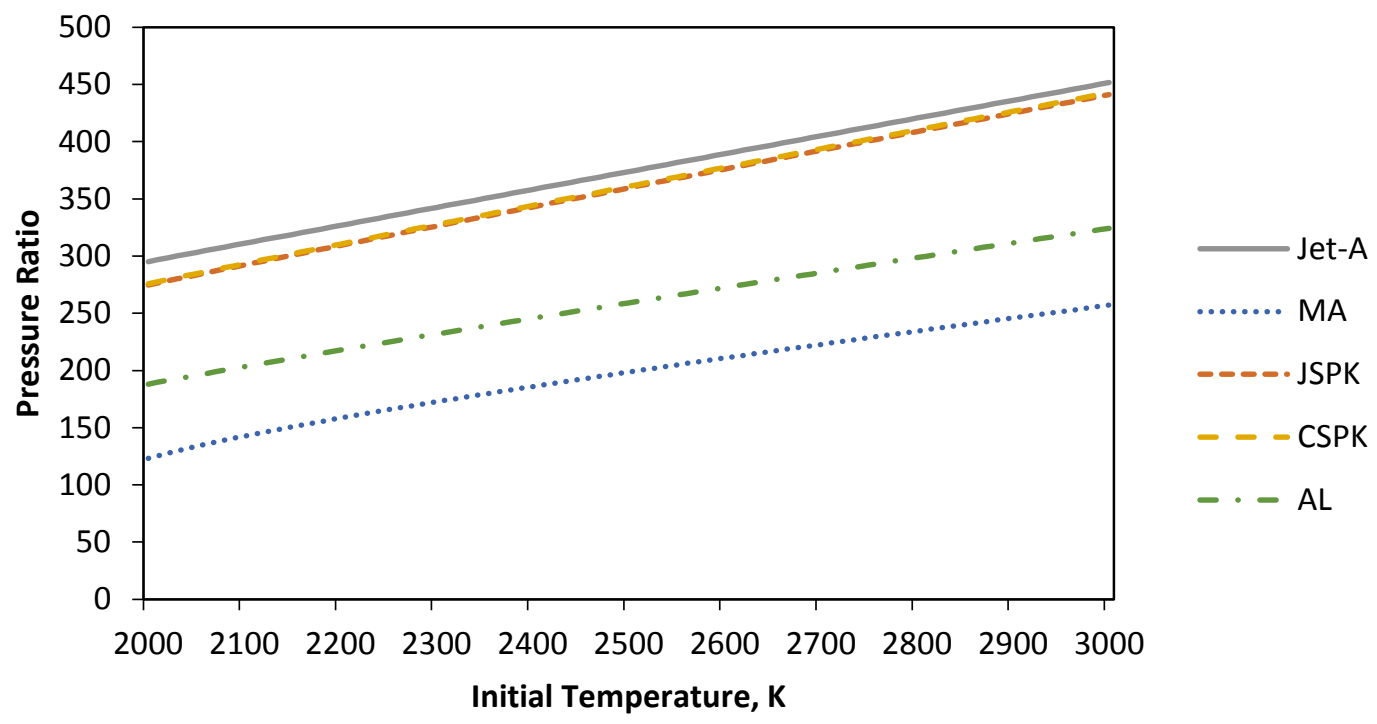

Figure 8. Comparison of pressure ratio at different initial temperature under influence of strong detonation $\left(P=1 \mathrm{~atm}, \mathrm{G}=6000 \mathrm{~kg} / \mathrm{s} \cdot \mathrm{m}^{2}\right)$.

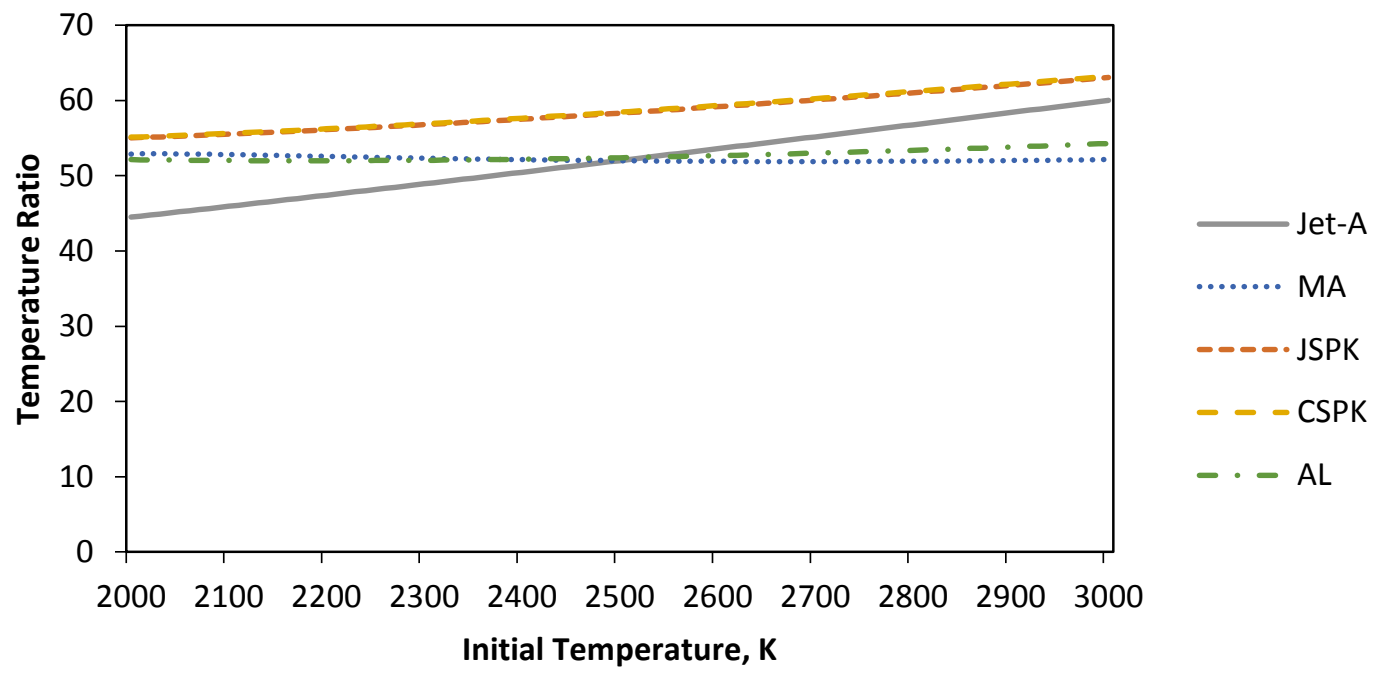

Figure 9. Comparison of temperature ratio at different initial temperature under the influence of strong detonation $\left(P=1 \mathrm{~atm}, \mathrm{G}=6000 \mathrm{~kg} / \mathrm{s} \cdot \mathrm{m}^{2}\right)$.

The effects of initial temperature to the specific volume and Mach number ratios variations are almost similar except that the gradient is much higher due to the changes of initial temperature (Fig. 10 and Fig. 11). Based on these comparisons, it may considerably be worth mentioning that the effects of initial temperature have significant changes to specific volume and Mach number ratios compared to the effects of initial mass flux. Consequently, it would require further modelling to understand the significant changes of specific volume and Mach number ratios in 
Jet-A, JSPK, and CSPK fuels. It is believed that these fuels have greater gradient and changes of specific volume and Mach number ratios at the minimum temperature of detonation.

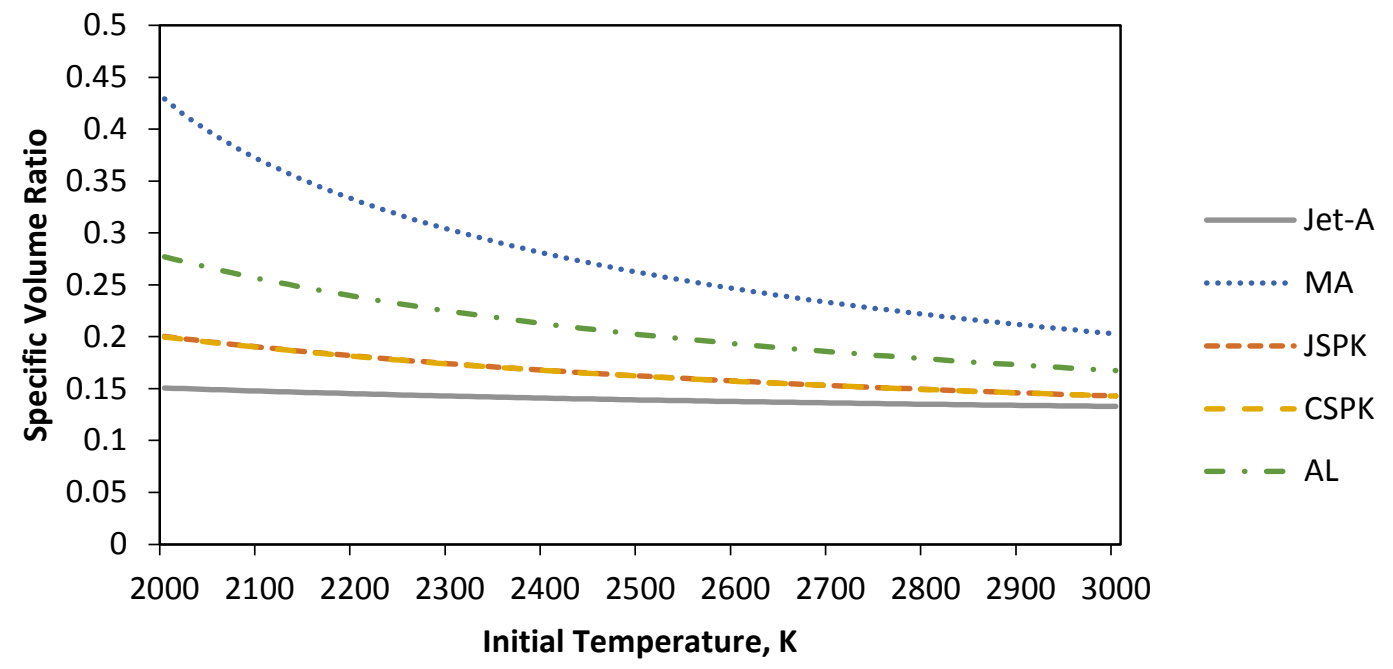

Figure 10. Comparison of specific volume ratio at different initial temperature under influence of strong detonation $\left(P=1 \mathrm{~atm}, \mathrm{G}=6000 \mathrm{~kg} / \mathrm{s} \cdot \mathrm{m}^{2}\right)$.

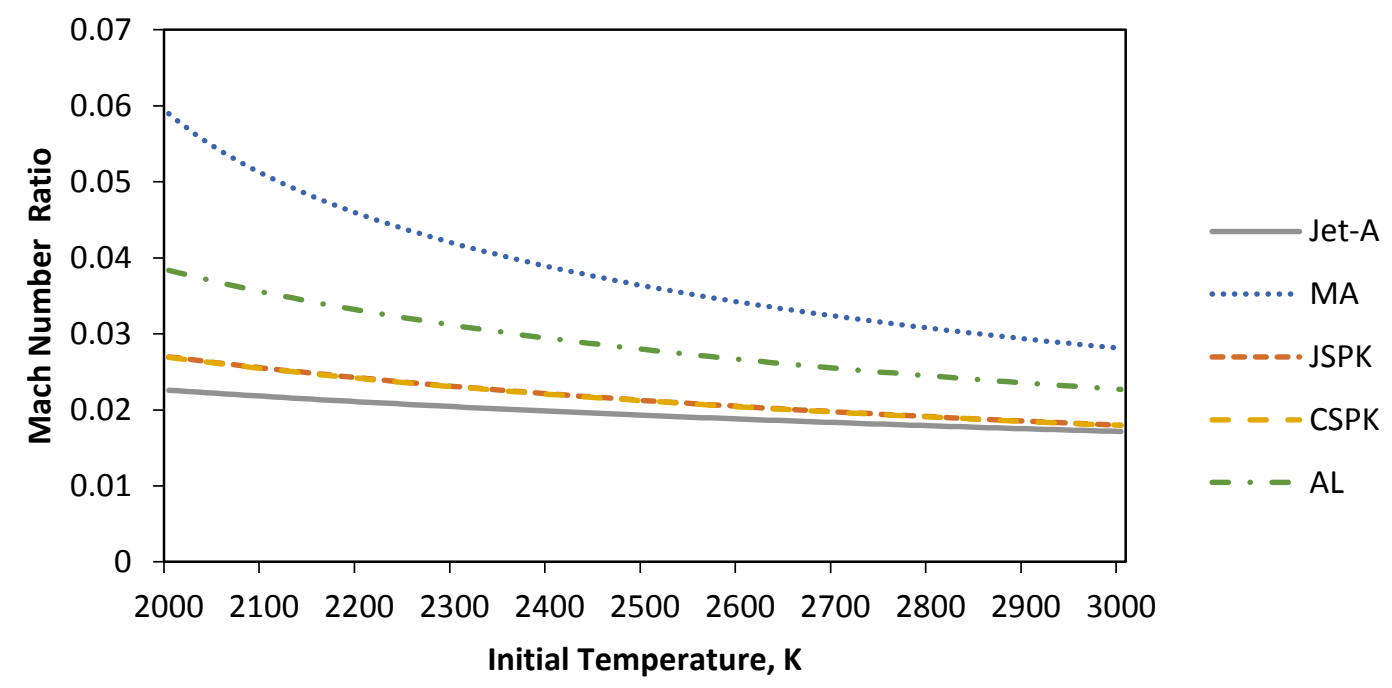

Figure 11. Comparison of Mach number ratio at different initial temperature under influence of strong detonation $\left(P=1 \mathrm{~atm}, \mathrm{G}=6000 \mathrm{~kg} / \mathrm{s} \cdot \mathrm{m}^{2}\right)$.

\section{Effects of initial pressure}

Initial pressure has significantly impacted the flow speed at the end of the tube as well becoming the limitation factor for the variation of initial pressure range for detonation to occur. To describe the limitation, microalgae fuel is chosen and the initial temperature is set to be $2000 \mathrm{~K}$ while varying the mass fluxes to $6200 \mathrm{~kg} / \mathrm{s} . \mathrm{m}^{2}, 6400 \mathrm{~kg} / \mathrm{s} . \mathrm{m}^{2}$, and $6600 \mathrm{~kg} / \mathrm{s} . \mathrm{m}^{2}$ respectively. The results are plotted based on the Mach number of the burned gas under both strong and weak shocks as shown in Fig. 12. At higher mass flux, the initial pressure can be increased to a wide range as compared to the one that has lower mass flux. For the given mass flux, as the initial pressure increase, the burned gas Mach number will increase for the strong wave. Conversely, weak waves have the tendency to reduce the burned gas flow. All burned gas flows are converging to the choking condition. Due to these limitations, higher 
mass flux is preferred in comparison to other alternative fuels as these could impose severe restrictions on the modelling.

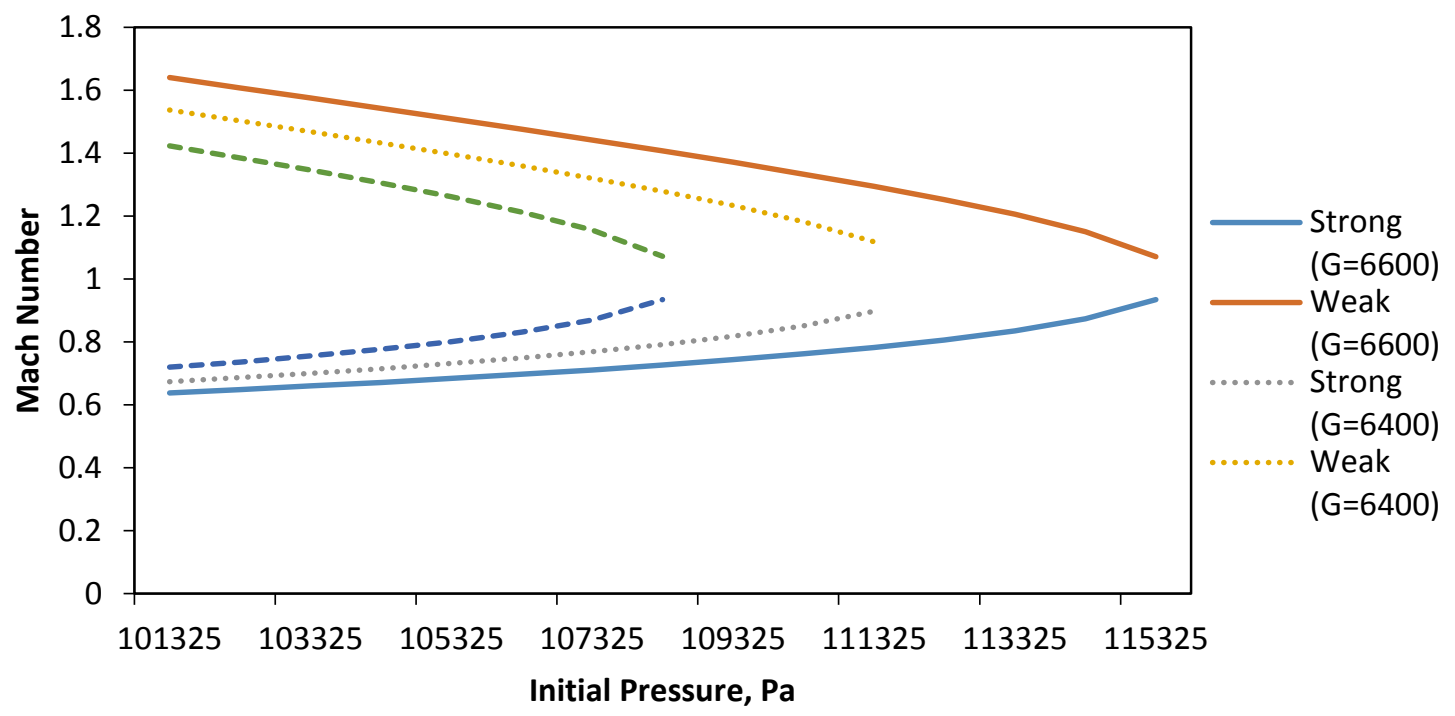

Figure 12. The influence of initial pressure and mass flux to Mach number for Microalgae Biofuel ( $\mathrm{T}=\mathbf{2 0 0 0 K})$.

A comparison of other alternative fuels based on Mach number, pressure, temperature, and specific volume ratios under the influence of strong detonation wave is illustrated in Fig. 13 - Fig. 17. Figure 13 shows the changes of the burned gas Mach number due to the effect of initial pressure. As previously mentioned, that strong detonation wave has resulted in an exponential increase in burned gas Mach number and specific volume ratios. However, it is observed that MA fuel is more sensitive to the changes of initial pressure compared to Jet-A fuel. In contrary, a high initial pressure will result in reductions in pressure and temperature ratios as shown in Fig. 14 and Fig. 15. It is worth noting that, for a given mass flux, this could impose a restriction for the further reduction of the pressure and temperature ratio changes especially MA fuel.

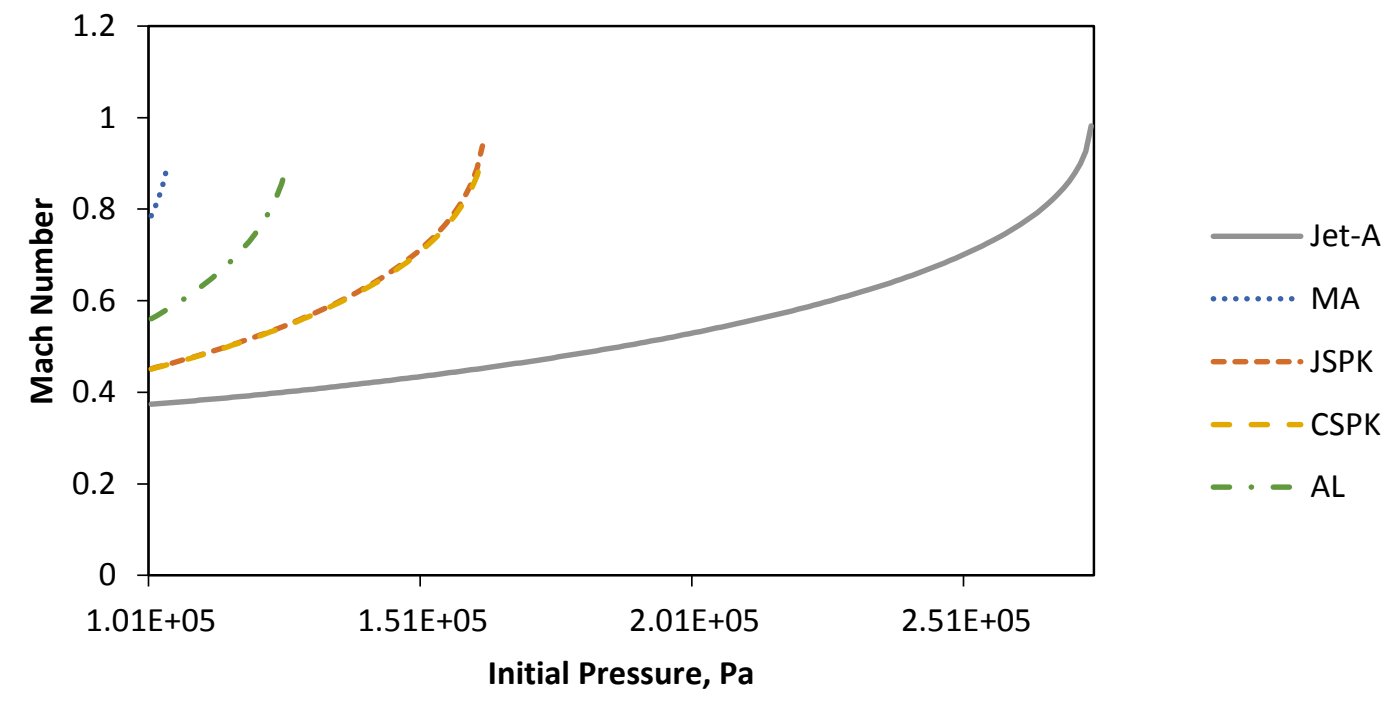

Figure 13. Comparison of Mach number at different initial pressure under influence of strong detonation $\left(\mathrm{T}=2000, \mathrm{G}=6000 \mathrm{~kg} / \mathrm{s} \cdot \mathrm{m}^{2}\right)$.

12

American Institute of Aeronautics and Astronautics 


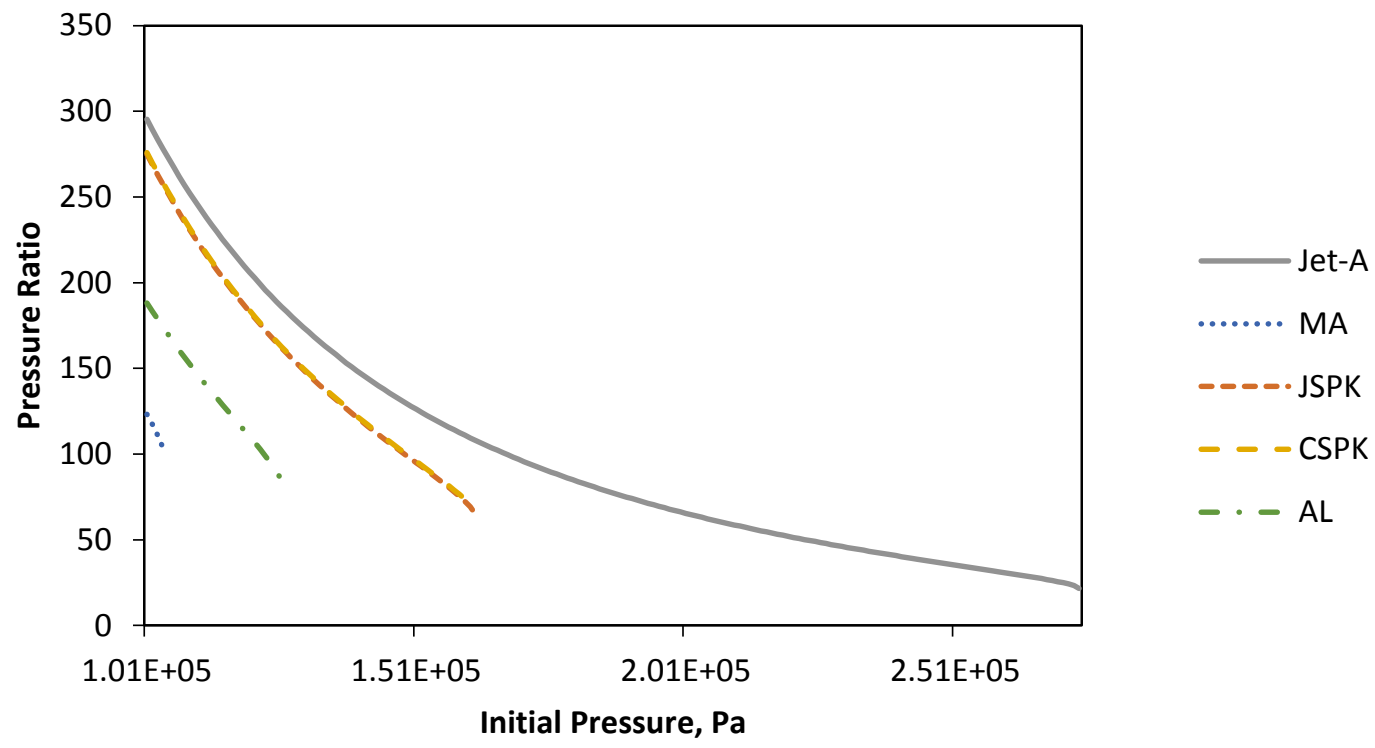

Figure 14. Comparison of pressure ratio at different initial pressure under influence of strong detonation $\left(\mathrm{T}=2000 \mathrm{~K}, \mathrm{G}=6000 \mathrm{~kg} / \mathrm{s} . \mathrm{m}^{2}\right)$.

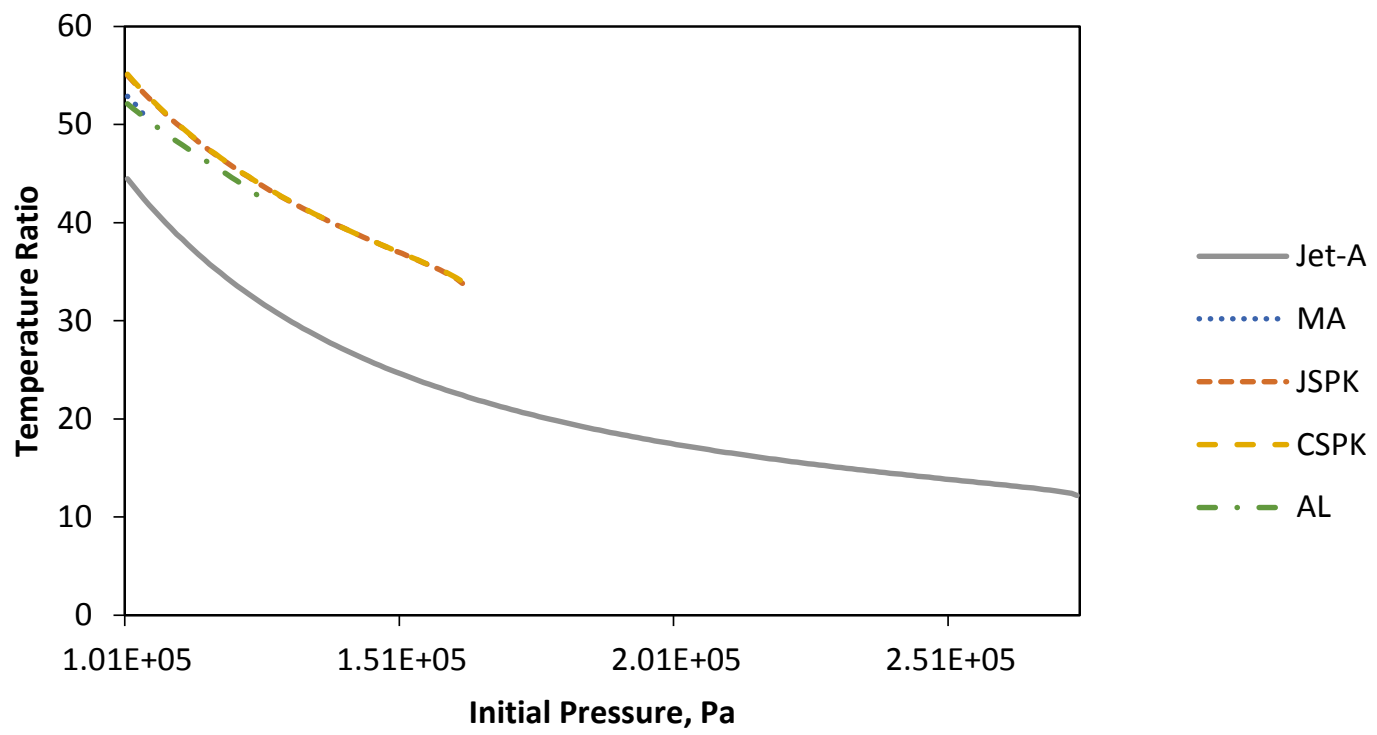

Figure 15. Comparison of temperature ratio at different initial pressure under influence of strong detonation $\left(\mathrm{T}=2000 \mathrm{~K}, \mathrm{G}=6000 \mathrm{~kg} / \mathrm{s} \cdot \mathrm{m}^{2}\right)$. 


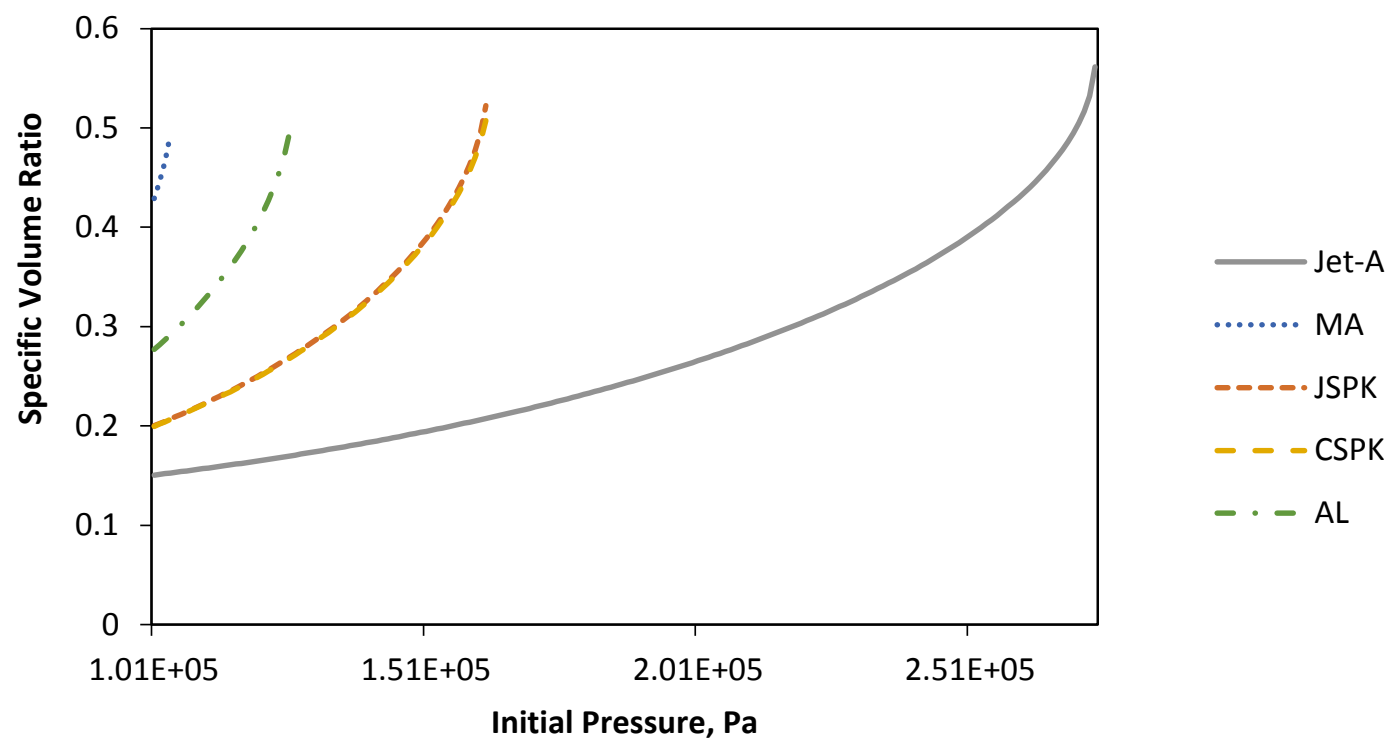

Figure 16. Comparison of specific volume ratio at different initial pressure under influence of strong detonation $\left(\mathrm{T}=\mathbf{2 0 0 0 \mathrm { K }}, \mathrm{G}=6000 \mathrm{~kg} / \mathrm{s} \cdot \mathrm{m}^{2}\right)$.

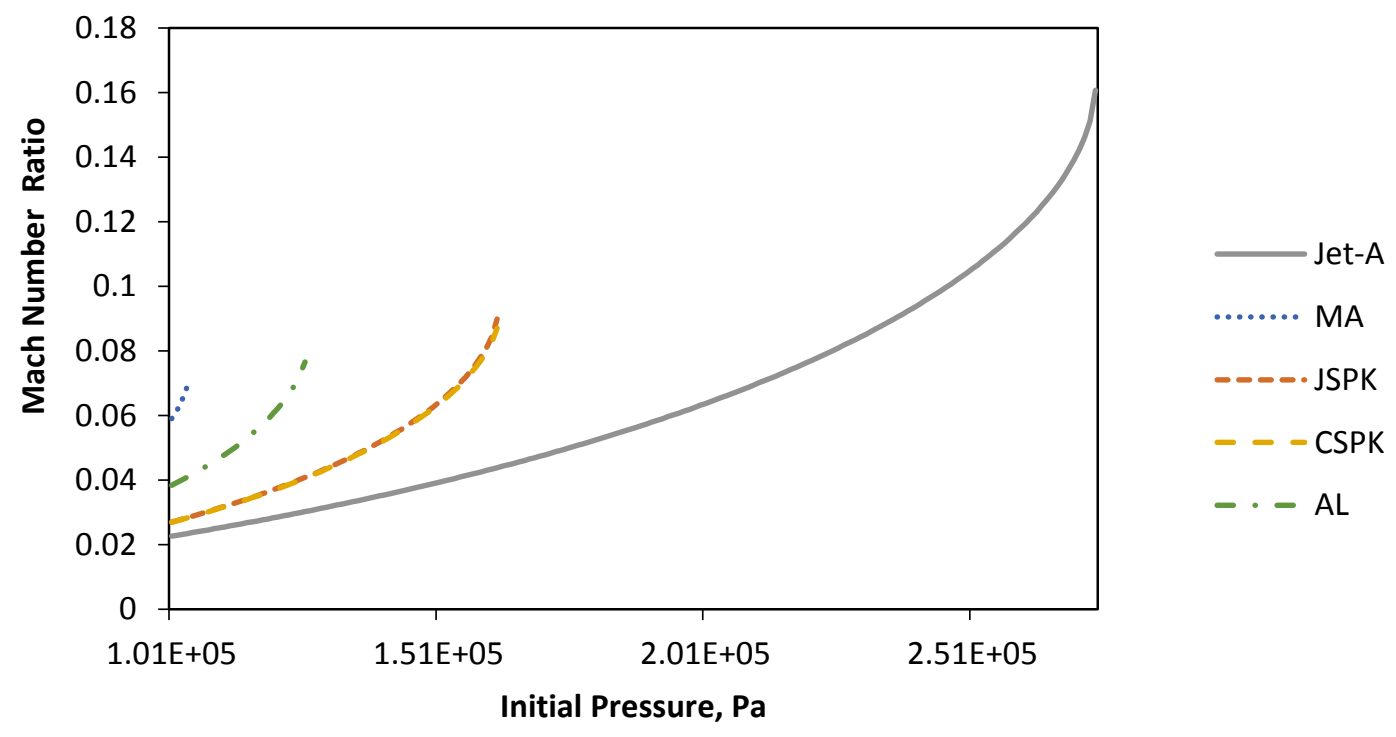

Figure 17. Comparison of Mach number ratio at different initial pressure under influence of strong detonation $\left(T=2000 \mathrm{~K}, \mathrm{G}=6000 \mathrm{~kg} / \mathrm{s} \cdot \mathrm{m}^{2}\right)$. 


\section{Conclusion}

The focus of this work was on the one-dimensional analysis of alternative fuels in a detonation mode of combustion. Comparison studies have been made to examine the feasibility and the effectiveness of these alternative fuels under the detonation conditions. Three stages of the process are modelled to visualise temporal variation of pressure, temperature and density ratios at every stage. Subsequently, the modelling is extended to understand the behaviour of the prescribed alternative fuels due to various changes in the initial conditions. The main conclusions of the work are as follows:

1. Applying expressions such as Rankine-Hugoniot equation, Rayleigh Line equation and Zel'dovich-von Neumann-Doering (ZND) model, and allowing for mole, mass fraction, and enthalpy-of-formation of the reactants, to find minimum initial conditions for detonation. Fuels (Jet-A, Jatropha Bio-synthetic Paraffinic Kerosene, Camelina Bio-synthetic Paraffinic Kerosene, Algae Biofuel, and Microalgae Biofuel) have been studied numerically to determine the changes in pressure, temperature and density ratios in three successive stages of the combustion process.

2. The influence of initial conditions, such as the effect of varying mass flux, temperature and pressure to the variation of pressure, temperature, specific volume, and Mach number ratios have been thoroughly investigated and discussed. It appears that Microalgae Biofuel is the most sensitive to the initial conditions.

3. The observed variation of mass flux could impose severe restrictions on the changes of the initial pressure. At higher mass flux, the initial pressure can be increased over a wide range.

4. The effects of initial temperature have a significant effect on specific volume and Mach number ratios, while variations in initial mass flux influence the pressure and temperature ratios most.

\section{Appendix}

\begin{tabular}{|c|c|c|c|c|}
\hline & MICROALGAE & ALGAE & JATROPHA & CAMELINA \\
\hline Density $(\mathrm{kg} / \mathrm{m3})$ & 886 & 883.6 & $864-880$ & - \\
\hline Cetane Number & 48.31 & $85-92$ & $46-55$ & 50.4 \\
\hline $\begin{array}{l}\text { Viscosity } \\
\left(\mathrm{mm} 2 / \mathrm{s} @ 4^{\circ} \mathrm{C}\right)\end{array}$ & 4.47 & 4.73 & $3.7-5.8$ & 3.80 \\
\hline Pour Point $\left({ }^{\circ} \mathrm{C}\right)$ & -12 & $-21--24$ & 5 & -7 \\
\hline Flash Point $\left({ }^{\circ} \mathrm{C}\right)$ & 165.5 & 179 & $163-238$ & 136 \\
\hline Heating Value (MJ/kg) & 40.045 & 40.72 & $38.5-42$ & 45.2 \\
\hline CFPP $\left({ }^{\circ} \mathrm{C}\right)$ & 18 & - & -1.2 & -3 \\
\hline Acid Value (mg/KOH) & 0.13 & 0.37 & 0.34 & - \\
\hline Cloud point $\left({ }^{\circ} \mathrm{C}\right)$ & -5.2 & 7 & 5 & 3 \\
\hline $\mathrm{C}(\%)$ & 61.52 & 68.30 & 76.57 & - \\
\hline H $(\%)$ & 8.50 & 8.30 & 12.21 & - \\
\hline $\mathbf{O}(\%)$ & 20.19 & 16.40 & 11.32 & - \\
\hline $\mathbf{N}(\%)$ & 9.79 & 6.20 & - & - \\
\hline $\begin{array}{l}\text { Kinematic viscosity } \\
\left(\mathbf{m m} / \mathbf{s} 2 @ \mathbf{4 0}^{\circ} \mathrm{C}\right)\end{array}$ & 33.06 & - & 4.75 & - \\
\hline Oxidation stability (h) & 8.83 & 6.76 & 5.0 & - \\
\hline $\begin{array}{l}\text { Iodine Value } \\
\text { (g I/100g) }\end{array}$ & $119.1 \mathrm{~g}$ & 97.12 & 109.5 & 152.8 \\
\hline $\begin{array}{l}\text { Sulfur Content } \\
(\text { ppm) }\end{array}$ & - & 8.1 & 12.9 & - \\
\hline Specific Gravity & - & $1.02 \mathrm{~g} / \mathrm{mL}$ & 0.876 & 0.882 \\
\hline References & $32-38$ & 39-42 & $43-45$ & 45 \\
\hline
\end{tabular}

15

American Institute of Aeronautics and Astronautics 


\section{Acknowledgments}

The lead author would like to acknowledge and thank International Islamic University Malaysia, Malaysia for the sponsoring his Ph.D. research work.

\section{References}

1 Kailasanath, K., "Recent Developments in the Research on Pulse Detonation Engines," AIAA Journal, vol. 41, Feb. 2003, pp. 145-159.

2 Frolov, S. M., "Natural-Gas-Fueled Pulse-Detonation Combustor," Journal of Propulsion and Power, vol. 30, Jan. 2014, pp. 41-46.

3 Li, J.-M., Teo, C. J., Lim, K. S., Wen, C.-S., and Khoo, B. C., "Deflagration to Detonation Transition by Hybrid Obstacles in Pulse Detonation Engines," 49th AIAA/ASME/SAE/ASEE Joint Propulsion Conference AIAA, San Jose, CA: American Institute of Aeronautics and Astronautics, 2013, pp. 1-12.

4 Eidelman, S., Grossmann, W., and Lottati, I., "Review of propulsion applications and numerical simulations of the pulsed detonation engine concept," Journal of Propulsion and Power, vol. 7, Nov. 1991, pp. 857-865.

5 Vutthivithayarak, R., Braun, E. M., and Lu, F. K., "Examination of the Various Cycles for Pulse Detonation Engines," 47th AIAA/ASME/SAE/ASEE Joint Propulsion Conference \& Exhibit, San Diego, California: American Institute of Aeronautics and Astronautics, 2011, pp. 1-11.

6 Blanco, G. M., "Numerical Modelling of Pressure Rise Combustion for Reducing Emissions of Future Civil Aircraft," Cranfield University, 2014.

7 Heiser, W. H., and Pratt, D. T., "Thermodynamic Cycle Analysis of Pulse Detonation Engines," Journal of Propulsion and Power, vol. 18, 2002.

$8 \quad$ Kailasanath, K., "Review of Propulsion Application of Detonation Waves," AIAA Journal, vol. 38, 2000.

9 Nikitin, V. F., Dushin, V. R., Phylippov, Y. G., and Legros, J. C., "Pulse detonation engines: Technical approaches," Acta Astronautica, vol. 64, Jan. 2009, pp. 281-287.

10 Li, J., Fan, W., Qiu, H., Yan, C., and Wang, Y.-Q., "Preliminary study of a pulse normal detonation wave engine," Aerospace Science and Technology, vol. 14, Apr. 2010, pp. 161-167.

11 Chan, S., and Liu, H., "Experimentally modified unsteady shock wave model for wave rotor design," 50th AIAA/ASME/SAE/ASEE Joint Propulsion Conference, Jul. 2014, pp. 1-12.

12 Akbari, P., and Nalim, R., "Review of Recent Developments in Wave Rotor Combustion Technology," Journal of Propulsion and Power, vol. 25, Jul. 2009, pp. 833-844.

13 Akbari, P., and Muller, N., "Performance Investigation of Small Gas Turbine Engines Topped with Wave Rotors," 39th AIAA/ASME/SAE/ASEE Joint Propulsion Conference and Exhibit, Huntsville, Alabama: American Institute of Aeronautics and Astronautics, 2003, pp. 1-11.

$14 \quad$ Akbari, P., and Nalim, R., "Analysis of Flow Processes in Detonative Wave Rotors and Pulse Detonation Engines," 44th AIAA Aerospace Sciences Meeting and Exhibit, Reno, Nevada: American Institute of Aeronautics and Astronautics, 2006, pp. 1-13.

15 Kaemming, T., "Integrated Vehicle Comparison of Turbo-Ramjet Engine and Pulsed Detonation Engine," Journal of Engineering for Gas Turbines and Power, vol. 125, 2003, pp. 257-262.

16 Qiu, H., Xiong, C., Yan, C., and Fan, W., "Propulsive Performance of Ideal Detonation Turbine Based Combined Cycle Engine," Journal of Engineering for Gas Turbines and Power, vol. 134, 2012, p. 081201.

17 Ebrahimi, H. B., and Merkle, C. L., "Numerical Simulation of a Pulse Detonation Engine with Hydrogen Fuels," Journal of Propulsion and Power, vol. 18, 2002.

18 Li, J., Fan, W., Yan, C., and Li, Q., "Experimental Investigations on Detonation Initiation in a Kerosene-Oxygen Pulse Detonation Rocket Engine," Combustion Science and Technology, vol. 181, Feb. 2009, pp. 417-432.

19 Ma, F., Choi, J., and Yang, V., "Thrust Chamber Dynamics and Propulsive Performance of Single-Tube Pulse Detonation Engines," 42nd AIAA Aerospace Sciences Meeting and Exhibit, Reno, Nevada: American Institute of Aeronautics and Astronautics, 2004, pp. 1-21.

20 Li, C., and Kailasanath, K., "A Numerical Study of Reactive Flows in Pulse Detonation Engines," 37th AIAA/ASME/SAE/ASEE Joint Propulsion Conference \& Exhibit, Salt Lake City, Utah: American Institute of Aeronautics and Astronautics, 2001.

21 Wu, Y., Ma, F., and Yang, V., "System Performance and Thermodynamic Cycle Analysis of Air-Breathing Pulse Detonation Engines," 40th AIAA Aerospace Sciences Meeting \& Exhibit, Reno, NV: American Institute of Aeronautics and Astronautics, 2002.

22 Hutchins, T. E., and Metghalchi, M., "Energy and Exergy Analyses of the Pulse Detonation Engine," Journal of Engineering for Gas Turbines and Power, vol. 125, 2003, p. 1075.

23 Hitch, B., "An Analytical Model of the Pulse Detonation Engine Cycle," 40th AIAA Aerospace Sciences Meeting \& Exhibit, Reno, NV: American Institute of Aeronautics and Astronautics, 2002.

24 Harris, P. G., Guzik, S., Farinaccio, R., Stowe, R. A., Whitehouse, D., Josey, T., Hawkin, D., Ripley, R., Link, R., Higgins, A. ., and Thibault, P. ., "Comparative Evaluation of Performance Models of Pulse Detonation Engines," 38th AIAA/ASME/SAE/ASEE Joint Propulsion Conference \& Exhibit, Indianapolis, Indiana: American Institute of

American Institute of Aeronautics and Astronautics 
Aeronautics and Astronautics, 2002.

Wintenberger, E., and Shepherd, J. E., “A Model for the Performance of Air-Breathing Pulse Detonation Engines,” 39th AIAA/ASME/SAE/ASEE Joint Propulsion Conference and Exhibit, Huntsville, Alabama: American Institute of Aeronautics and Astronautics, 2003, pp. 1-16. Yi, T.-H., Lou, J., Turangan, C., Choi, J.-Y., and Wolanski, P., "Propulsive Performance of a Continuously Rotating Detonation Engine," Journal of Propulsion and Power, vol. 27, Jan. 2011, pp. 171-181.

27 Lu, F. K., and Braun, E. M., "Rotating Detonation Wave Propulsion: Experimental Challenges, Modeling, and Engine Concepts," Journal of Propulsion and Power, vol. 30, Sep. 2014, pp. 1125-1142. Kentfield, J. A. C., "Thermodynamics of Airbreathing Pulse-Detonation Engines," Journal of Propulsion and Power, vol. 18, 2002, pp. 1170-1175.

Brophy, C. M., Sinibaldi, J. O., and Damphousse, P., "Initiator Performance for Liquid-Fueled Pulse Detonation Engines," 40th AIAA Aerospace Sciences Meeting \& Exhibit, Reno, NV: American Institute of Aeronautics and Astronautics, 2002.

Kailasanath, K., Patnaik, G., and Li, C., "The flowfield and performance of pulse detonation engines," Proceedings of the Combustion Institute, 2002, pp. 2855-2862.

31 Turns, S., Introduction to Combustion: Concepts and Application, McGraw-Hill, 2000.

32 Tüccar, G., and Aydın, K., "Evaluation of methyl ester of microalgae oil as fuel in a diesel engine," Fuel, vol. 112, Oct. 2013, pp. 203-207.

33 Amin, S., "Review on biofuel oil and gas production processes from microalgae," Energy Conversion and Management, vol. 50, Jul. 2009, pp. 1834-1840.

Chen, Y.-H., Huang, B.-Y., Chiang, T.-H., and Tang, T.-C., "Fuel properties of microalgae (Chlorella protothecoides) oil biodiesel and its blends with petroleum diesel," Fuel, vol. 94, Apr. 2012, pp. 270-273. Brennan, L., and Owende, P., "Biofuels from microalgae-A review of technologies for production, processing, and extractions of biofuels and co-products," Renewable and Sustainable Energy Reviews, vol. 14, Feb. 2010, pp. 557-577. Atabani, A. E., Silitonga, A. S., Badruddin, I. A., Mahlia, T. M. I., Masjuki, H. H., and Mekhilef, S., "A comprehensive review on biodiesel as an alternative energy resource and its characteristics," Renewable and Sustainable Energy Reviews, vol. 16, May 2012, pp. 2070-2093. Rinaldini, C. A., Mattarelli, E., Magri, M., and Beraldi, M., "Experimental Investigation on Biodiesel from Microalgae as Fuel for Diesel Engines," SAE Technical Paper, 2014. Ahmad, A. L., Mat Yasin, N. H., Derek, C. J. C., and Lim, J. K., "Microalgae as a sustainable energy source for biodiesel production : A review," Renewable and Sustainable Energy Reviews, vol. 15, 2011, pp. 584-593.

Makarevičienè, V., Lebedevas, S., Rapalis, P., Gumbyte, M., Skorupskaite, V., and Žaglinskis, J., "Performance and emission characteristics of diesel fuel containing microalgae oil methyl esters," Fuel, vol. 120, Mar. 2014, pp. $233-239$. Alcaine, A. A., "Biodiesel from microalgae," 2007.

41 Haik, Y., Selim, M. Y. E., and Abdulrehman, T., "Combustion of algae oil methyl ester in an indirect injection diesel engine," Energy, vol. 36, Mar. 2011, pp. 1827-1835.

Jena, U., Vaidyanathan, N., Chinnasamy, S., and Das, K. C., "Evaluation of microalgae cultivation using recovered aqueous co-product from thermochemical liquefaction of algal biomass," Bioresource Technology, vol. 102, 2011, pp. 3380-3387.

Ashraful, A. M., Masjuki, H. H., Kalam, M. A., Fattah, I. M. R., Imtenan, S., Shahir, S. A., and Mobarak, H. M., "Production and comparison of fuel properties, engine performance, and emission characteristics of biodiesel from various non-edible vegetable oils : A review," Energy Conversion and Management, vol. 80, 2014, pp. $202-228$. Giakoumis, E. G., "A statistical investigation of biodiesel physical and chemical properties , and their correlation with the degree of unsaturation," Renewable Energy, vol. 50, 2013, pp. 858-878.

45 Hoekman, S. K., Broch, A., Robbins, C., Ceniceros, E., and Natarajan, M., "Review of biodiesel composition , properties , and specifications," Renewable and Sustainable Energy Reviews, vol. 16, 2012, pp. 143-169. 
2016-07-31

\section{Comparative analysis of alternative fuels in detonation combustion}

Azami, M. H.

American Institute of Aeronautics and Astronautics

Azami, M. H., Savill, M. A. (2016) Comparative analysis of alternative fuels in detonation combustion, 52nd AIAA/SAE/ASEE Joint Propulsion Conference, Propulsion and Energy

Forum, Salt Lake City, Utah, United States of America, 25-27 July 2016

http://dx.doi.org/10.2514/6.2016-5104

Downloaded from Cranfield Library Services E-Repository 